\title{
Anion Exchange Membrane Electrolyzers as Alternative for the Upgrading of Biomass derived Molecules
}

Luis A. Diaz, Tedd E. Lister, Cathy Rae, Nathan D. Wood

June 2018

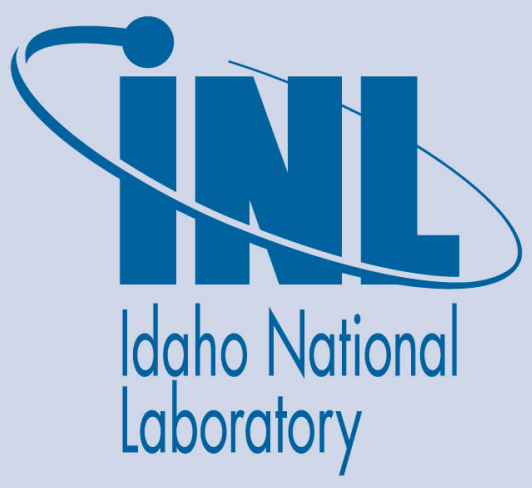

The INL is a U.S. Department of Energy National Laboratory operated by Battelle Energy Alliance 


\title{
Anion Exchange Membrane Electrolyzers as Alternative for the Upgrading of Biomass derived Molecules
}

\author{
Luis A. Diaz, Tedd E. Lister, Cathy Rae, Nathan D. Wood
}

June 2018

Idaho National Laboratory Idaho Falls, Idaho 83415

http://www.inl.gov

Prepared for the U.S. Department of Energy

Office of Energy Efficiency and Renewable Energy Under DOE Idaho Operations Office Contract DE-AC07-05ID14517 


\title{
Anion Exchange Membrane Electrolyzers as Alternative for the Upgrading of Biomass Derived Molecules
}

\author{
Luis A. Diaz*, Tedd E. Lister*, Cathy Rae, and Nathan D. Wood \\ Biological and Chemical Processing Department \\ Idaho National Laboratory \\ P.O Box 1625 \\ Idaho Falls, ID 38415-3731, USA
}

Fax: (1) 208-526-4822

A research paper submitted to

ACS Sustainable Chemistry \& Engineering

for consideration for publication

* Corresponding Author. Tel.: +1 208526 7411. Fax: +1 208526 4822. E-mail address: luis.diazaldana@inl.gov (L.A. Diaz)

* Corresponding Author. Tel.: +1 208526 4320. Fax: +1 208526 4822. E-mail address: tedd.lister@inl.gov (T.E. Lister). 


\begin{abstract}
Upgrading biomass derived platform molecules to fuels or chemicals provides a unique alternative for the substitution of fossil sources with renewables. Electrochemical reduction (ECR) is one of the upgrading technologies, alternative to catalytic reduction, which only requires electricity as the energy input, which can be derived from carbon free energy sources. Moreover, ECR does not require external addition of hydrogen, as this can be generated in-situ. In this work an anion exchange membrane (AEM) electrolyte assembly (MEA) has been tested for the efficient reduction of biomass derived molecules, and compared with a cation exchange membrane (CEM) MEA. The cathode electrocatalyst has been modified with the addition of hydrophobicity and anion exchange ionomers, and incorporated onto an anion exchange membrane. Electrochemical experiments were performed with a metal free electrocatalyst in the presence and absence of surrogate compounds. The results showed that changes in the catalyst formulation can increase the overpotential for the competing hydrogen evolution reaction (HER), while significantly enhancing the reduction of the organic molecules. Bulk electrolysis experiments demonstrated higher efficiencies for furfural ECR in an AEM-MEA vs. AEM-CEM, reaching conversions up to $94 \%$ at $50 \mathrm{~mA} \mathrm{~cm}^{-2}$ and in the absence of supporting electrolyte. Moreover, AEM-MEA was able to facilitate water management during the reduction process and contribute to the separation of small carboxylic acids.
\end{abstract}

Keywords: Electrochemical reduction, biomass derived platform molecules, furfural, anion exchange membrane 


\section{Introduction}

Biomass derived fuels and chemicals are a sustainable alternative to those derived from petroleum, yet leverage many of their advantages such as energy density, rapid fueling, existing infrastructure, mature technology, etc. The substitution of fossil resources requires the production of commodity chemicals that can be obtained from the comprehensive processing of biomass through three main steps: preprocessing, valorization, and refinement.

The U.S. Department of Energy (DOE) has defined 12 top biomass derived platform molecules (BDPM) that have the greatest potential for chemicals and fuels production (Figure 1). ${ }^{1,2}$ The BDPM building blocks, rather than being supplied by petrochemicals, can be obtained after biomass pre-processing through the fractionation and/or deconstruction of the cellulose, hemicellulose, and lignin, which are the three major constituents of the lignocellulosic biomass. ${ }^{3-}$ ${ }^{5}$ However, as can be seen in Figure 1, there are clear differences between BDPM and the petrochemical building blocks. ${ }^{2}$ These differences come from the nature and composition of the original sources, specifically from the large oxygen content present in carbohydrate polymers that compose lignocellulosic biomass, in comparison with fossil sources. ${ }^{4}$

The high concentration of oxygen, carbonyls, and phenolic groups present in the BDPM directly translate in poor physicochemical characteristics for their incorporation into the current refinery infrastructure. While refinery schemes are based on the fractionation and processing of molecules with similar numbers of carbons, which correlate to boiling point, oxygenated compounds feature higher boiling points that significantly vary with the degree of oxygenation and functional groups rather than number of carbons. On the other hand, lower API gravity (higher density) of the oxygenated molecules could impact the economy of the refining industry, 
in which sales are based on volumetric quantities. ${ }^{6}$ Therefore, as a first valorization step, BDPM should be reduced (hydrogenated and deoxygenated) into molecules that better fit the current refining industry.

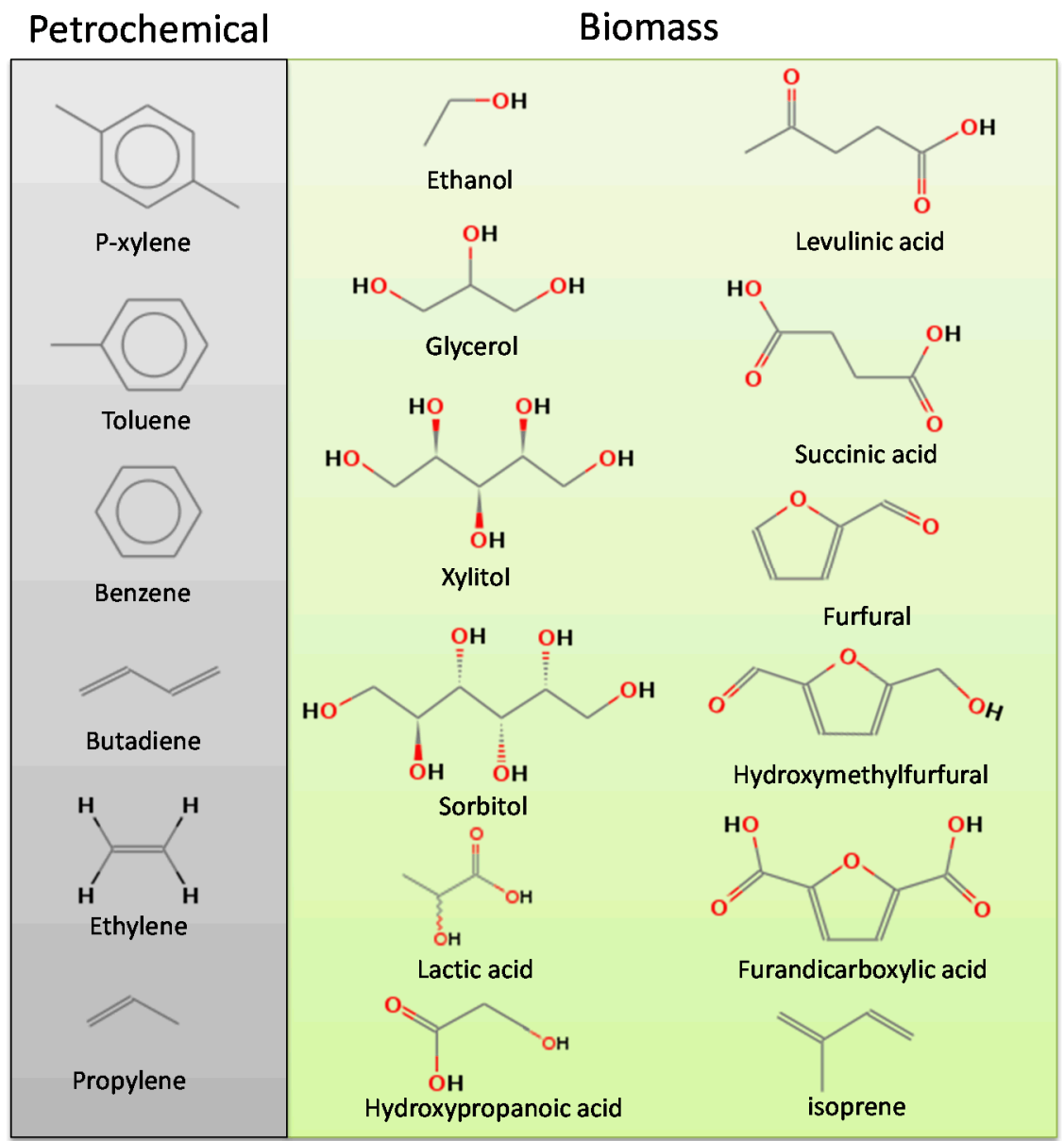

Figure 1. Platform molecules derived from petrochemicals and biomass ${ }^{2}$

Catalytic hydrotreatment is the most studied and developed technology for the hydrogenation and hydrogenolysis of BDPM. ${ }^{5,7}$ However, catalytic hydrotreatment requires large amounts of hydrogen, normally produced from fossil natural gas, at pressures higher than 81 atm and temperatures over $425^{\circ} \mathrm{C} .{ }^{9}$ Because of the high processing conditions, lower stability of the 
oxygenated compounds, and carbon footprint, a more efficient process that can be operated solely on carbon free energy sources should be developed.

Electrochemical reduction (ECR) is one of the technologies that only requires electricity as an energy input; therefore, it can be directly supplied by renewable and carbon free energy sources, such as solar, wind, and nuclear. Moreover, ECR does not require external addition of hydrogen as the electron/proton transfer occurs at the electrode surface. ${ }^{10}$ These characteristics make electrochemical processing suitable for distributed applications. ECR also can be performed at mild operating conditions of pressure and temperatures. ${ }^{11}$

Currently, there is a growing research interest in the development of ECR processes, electrocatalyst evaluation, reaction pathways, and product distribution for several model molecules that include, but are not limited to furfural, acetophenone, guaiacol, phenol, benzaldehyde, and levulinic acid. ${ }^{12-22}$

ECR is not a new field, as there is a significant body of work on ECR of various organic compounds, which include sugars and unsaturated acids. ${ }^{23}$ ECR of unsaturated carbons has being found to proceed at high current efficiencies. ${ }^{20,23}$ On the other hand, reduction of carbonyl bonds $(\mathrm{C}=\mathrm{O})$ generally proceeds with lower current efficiencies, with most of the cathodic current going towards the hydrogen evolution reaction (HER). ${ }^{20}$ This is mostly related to the lower carbon-carbon $\pi$ bond strength in comparison to the carbon-oxygen bond, which makes the double bound saturation thermodynamically more favorable. ${ }^{24}$ While HER produces a valuable side product, it is desirable to increase the current (Faradaic) efficiency for ECR of BDPM.

Several approaches have been utilized by researchers in order to improve the efficiencies of the ECR process. These include the development of suitable electrocatalysts, ${ }^{22,25}$ the control of 
the electrode polarization by means of applying low current densities below $10 \mathrm{~mA} \mathrm{~cm}{ }^{-2}$, and/or the use of co-solvents, such as, methanol, ethanol, and acetonitrile to suppress the HER. ${ }^{16,17,19}$ Although these approaches are valuable to enhance the understanding of reaction mechanisms, products, and pathways, their direct contribution towards the development of a feasible scalable process is limited. While fundamental understanding of the kinetics and catalytic processes will contribute to the enhancement of product selectivity and efficiency, their development cannot be isolated from the other phenomena affecting the ECR process.

Operation at low current densities will require large electrode surface areas at the industrial scale, resulting in prohibitively high capital expenses. Use of co-solvents will obligate the inclusion of additional separation processes and possible modification of the colligative properties of the solutions. However, most of the research has been limited to electrochemical configurations in three electrode cells and H-cells, which require the addition of electrolytes. ${ }^{11,12,}$ 15,19

A relatively small body of research has been performed using MEAs, to avoid the addition of electrolytes. ${ }^{17,20,26}$ The work is limited to proton exchange membranes where $\mathrm{H}^{+}$, produced at the anode from the oxidation of water and/or $\mathrm{H}_{2}$, is transferred to the cathode through cation exchange membranes (CEM). Low current efficiencies are reported for the reduction of carbonyl groups in contrast with the reduction of unsaturated molecules. ${ }^{23,24}$ Moreover, water transfer from the anode to the cathode, mostly enhanced by electro-osmotic drag, present other issues. Water, which is required for membrane function, may cause the dilution of the water soluble substrates or phase separation into emulsions such those seen from bio-oil, a complex micro emulsion rich in BDPM obtained from the pyrolysis of biomass. ${ }^{4}$ 
In this paper, anion exchange ionomers (AEI) and an anion exchange membrane (AEM) are assessed for the ECR of water soluble BDPM. Thereby, water, instead of electrochemically generated hydrogen protons, should serve as hydrogen source for the reduction of BDPMs. Experimental comparisons are performed against cation exchange ionomers (CEI), and CEM based MEA using surrogate molecules without targeting specific products (Figure 2). Furfural, as well as a surrogate mixture composed of six different carbonyl and phenolic containing molecules, have been used as a model for the reduction of BDPMs.
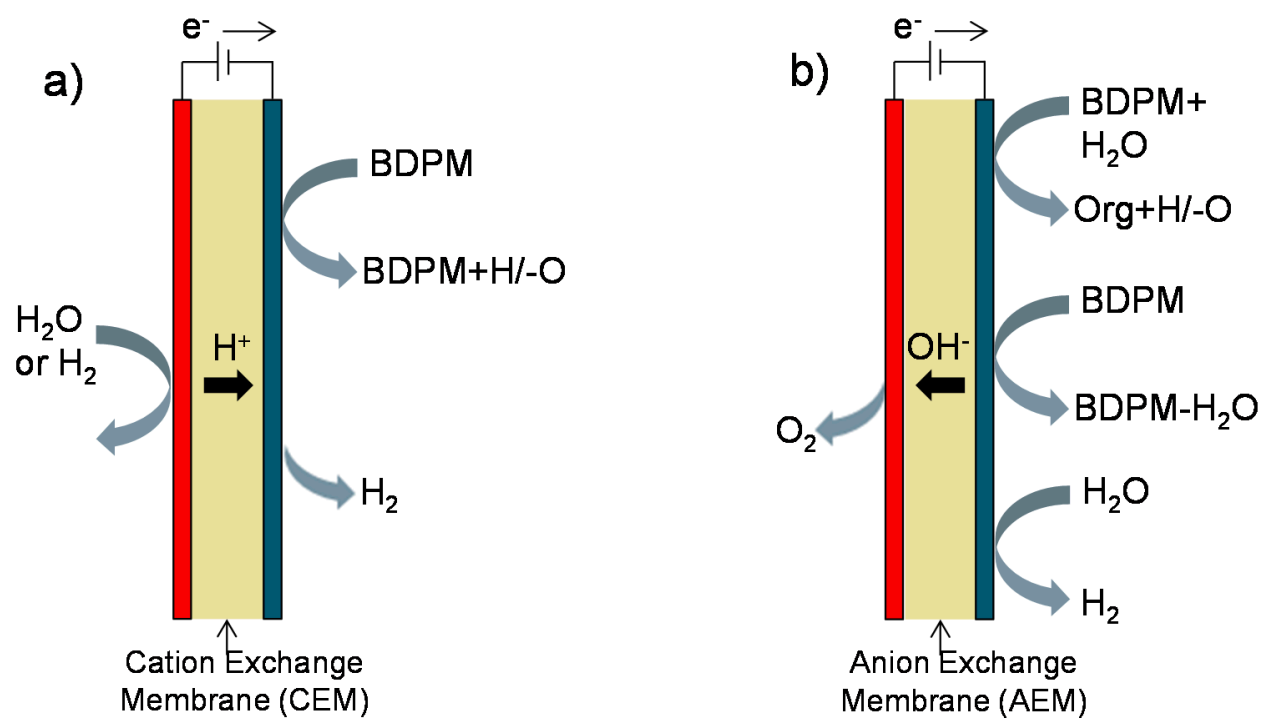

Figure 2. Scheme of CEM and AEM MEAs for the upgrading for BDPM

It is expected that through the use of AEI and AEM, the HER mechanism will switch from acid to alkaline media (reaction $\mathrm{R} 1$ to reaction $\mathrm{R} 2$ ), even in low $\mathrm{pH}$ electrolytes. This is due to the decrease of proton conductivity and generation of higher $\mathrm{pH}$ on the cathode surface. The addition of hydrophobicity to the electrocatalyst through the inclusion of hydrophobic materials, such as polytetrafluoroethylene (PTFE), should contribute to control the mass transfer of water to the active sites enhancing the reduction of the organic molecules over the HER. 


$$
\begin{array}{cc}
2 \mathrm{H}^{+}+2 e^{-} \rightarrow \mathrm{H}_{2} & 0 \text { VVs.SHE } \\
\mathrm{H}_{2} \mathrm{O}+2 e^{-} \rightarrow \mathrm{H}_{2}+2 \mathrm{OH}^{-} & -0.829 \text { V vs. SHE }
\end{array}
$$

Carbon based electrocatalysts in the absence of metals were studied at two different scales for electrochemical evaluation and bulk electrolysis, respectively.

\section{Materials and methods}

Electrocatalyst preparation. Cathode electrocatalyst inks were prepared with Vulcan carbon XC 72R. 5 wt\% Nafion ${ }^{\circledR}$ perfluorinated resin solution (Sigma-Aldrich), and 5 wt \% Fumion prepared from shredded Fumion FAA-3 membranes dissolved in 1-propanol, were used as CEI and AEI, respectively. Vulcan carbon and ionomer solution were mixed in butyl acetate for the CEI, and 1-propanol for the AEI, and then sonicated for 30 min. After sonication, a $60 \% \mathrm{PTFE}$ suspension in water was added to the catalyst ink formulation when hydrophobicity was desired, followed by agitation with a stir bar for an additional 30 minutes. The quantities of ionomer and/or binder (PTFE) added to the electrocatalyst were estimated to obtain a final electrocatalyst layer with $80 \mathrm{wt} \%$ carbon $20 \mathrm{wt} \%$ ionomer/binder. For the evaluation of the cathode electrocatalyst, $8 \mu \mathrm{L}$ of the ink solution was dropped on an EG\&G glassy carbon (GC) rotating disk electrode (RDE), which measured $4 \mathrm{~mm}$ in diameter. The ink was air dried for $1 \mathrm{~h}$ before use.

Scale-up of the electrocatalyst in MEAs was performed using either Nafion ${ }^{\circledR}-117$ or Fumasep ${ }^{\circledR}$ FAA-3-PK-130 membrane. The cathode catalyst ink was painted on both sides of a Toray carbon paper TGP-H-030 $\left(1.602 \mathrm{~cm}^{2}\right.$ for the $\mathrm{H}$-cell electrodes and $10 \mathrm{~cm}^{2}$ for the flow cell experiments). Painted carbon electrodes with catalyst loading ca. $3 \mathrm{mg} \mathrm{cm}^{-2}$ were hot pressed 
onto the Nafion ${ }^{\circledR}$ and Fumasep ${ }^{\circledR}$ membranes, and against a Pt plated sinter titanium sheet (Anode).

CEM-MEAs were pressed for 90 seconds at $120^{\circ} \mathrm{C}$ and $4.8 \mathrm{mPa}$ of pressure. The AEMMEA, prepared with Fumasep ${ }^{\circledR}$ FAA-3-PK-130 previously transformed into the hydroxyl form in $1 \mathrm{M} \mathrm{NaOH}$ for $24 \mathrm{~h}$, was hot pressed for three minutes at $68^{\circ} \mathrm{C} 4.8 \mathrm{mPa}$ of pressure.

Electrochemical evaluation. Electrocatalyst evaluation was performed in a three electrode undivided cell. The painted GC RDE electrode was the working electrode and a platinum ring was used as the auxiliary electrode. Cathode potentials were measured versus a BASI saturated $\mathrm{Ag} / \mathrm{AgCl}$ reference electrode. However, for consistency all the electrode potentials have been corrected for ohmic resistance and are reported vs. reversible hydrogen electrode (RHE). The procedure for potential conversion and compensation is presented in the supporting information. All the electrochemical analyses, along with the bulk electrolysis, were performed using a Solartron 1470 E potentiostat. Electrochemical impedance spectroscopy was performed to determine the ohmic resistance for the MEAs using a Biologic SP 300 potentiostat.

A mixture containing $5 \mathrm{wt} \%$ acetic and $3 \mathrm{wt} \%$ formic acid in DI water $(\mathrm{pH}=1.9$ and conductivity of $5.12 \mathrm{mS} \mathrm{cm}^{-1}$ ) was used as the electrolyte (acid electrolyte). The use of some electrolyte is required in the undivided cell configuration to allow ionic conductivity. Although, both formic and acetic acid are weak electrolytes, they were considered suitable for this study as they are usually co-produced during the hydrolysis of biomass. ${ }^{27}$ The electrolyte composition was chosen based on the typical composition of biomass derived pyrolysis oil. ${ }^{28}$ Four different electrocatalyst formulations were tested: Vulcan carbon-Nafion ${ }^{\circledR}(A)$, Vulcan ${ }^{\circledR}$ carbon-PTFE (B), Vulcan ${ }^{\circledR}$ carbon-Fumion ${ }^{\circledR}(C)$, and Vulcan ${ }^{\circledR}$ carbon-Fumion ${ }^{\circledR}-$ PTFE (D). Cyclic 
voltammetry from 0 to $-1.5 \mathrm{~V}$ vs. $\mathrm{Ag} / \mathrm{AgCl}$ was performed in the acid electrolyte, in the presence and absence of $50 \mathrm{mM}$ of the surrogate.

Furfural was selected as a model surrogate because it is typically obtained from the deconstruction of lignocellulosic biomass. ${ }^{7}$ For each one of the electrocatalyst formulations, a conditioning procedure (20 CV cycles at $10 \mathrm{mV} \mathrm{s}^{-1}$ in the electrolyte solution followed by rinsing with DI water under stirring at $2000 \mathrm{rpm}$ ) was performed. After electrochemical evaluation with furfural, the catalyst with the best performance was tested in a surrogate mixture with different carbonyl and oxygenated molecules. The surrogate mixture contained $50 \mathrm{mM}$ of the following: furfural, benzaldehyde, phenol, p-methoxythiophenol, acetophenone, and valeraldehyde in the acid electrolyte. CV experiments were supplemented with a potential staircase analysis where an estimation measurement of the current efficiency was obtained.

The electrocatalyst formulation with the best performance was incorporated into an MEA: using a Nafion ${ }^{\circledR}-117$ membrane as a CEM, or a Fumasep ${ }^{\circledR}$ FAA-3-PK-130 in the hydroxyl form as AEM. CV experiments were conducted in the presence and absence of organic surrogates in the cathode solution using a customized H-cell based in a cell configuration suggested elsewhere. ${ }^{29,30}$ For this H-cell the membranes were extended in the lower part of the cell and immersed in the acid electrolyte to maintain ionic contact between the cathode and the reference electrode located outside of the H-cell. A description of the H-cell setup can be found in the supporting information Figure S1. Constant current experiments were performed for the furfural solution and the surrogate mixture.

Bulk electrolysis. Flow cell tests were performed using a $10 \mathrm{~cm}^{2}$ MEA prepared with the cathode formulation that demonstrated the best performance. The MEA was pressed against two titanium flow plates with serpentine channels. The cell was designed and built in-house. Bulk 
electrolysis tests were performed at $50 \mathrm{~mA} \mathrm{~cm}^{-2}$ for $0.1 \mathrm{M}$ furfural solutions in acid electrolyte and in deionized (DI) water (no electrolyte). Cole Parmer MasterFlex C/L peristaltic pumps were used to recirculate the catholyte and anolyte solutions at approximately $10 \mathrm{ml} \mathrm{min}^{-1}$. Qualitative analyses were performed to identify the products present in catholyte and anolyte solutions using a Shimadzu 2010 Plus gas chromatograph (GC) equipped with a TQ 8040 mass spectrometer and a Restek (Bellefonte, PA) Rtx-5 column (30 m, $0.25 \mathrm{~mm}$ ID, $0.25 \mu \mathrm{M} \mathrm{df}$ ). External calibration was performed with standards ranging from 0 to $100 \mathrm{mM}$ of furfural and furfuryl alcohol for quantitative analysis.

\section{Results}

Electrochemical evaluation. Cyclic voltammetry experiments were performed for the four cathode electrocatalyst formulations, $\mathrm{A}$ to $\mathrm{D}$, at a scan rate of $10 \mathrm{mV} \mathrm{s}^{-1}$ and under quiescent conditions in acid electrolyte. The CVs obtained for each of the electrocatalyst formulations, in the absence of furfural, were recorded after conditioning ( $>20$ cycles) and are presented in Figure 3. It can be observed that the addition of PTFE (for hydrophobicity) and the substitution of cation exchange ionomers with AEI shifts the onset potential negative for the HER. For example, a negative shift in the HER onset potential of ca. $300 \mathrm{mV}$ was observed from the formulation A (Nafion $\left.{ }^{\circledR}\right)$ to the formulation $\mathrm{C}\left(\right.$ Fumasep $\left.{ }^{\circledR}\right)$. These results indicate that HER overpotential can be increased by decreasing the proton conductivity on the electrode composition. It is anticipated that a higher $\mathrm{pH}$ is generated on the cathode catalyst with the AEI, contributing to the HER onset potential negative shift. 


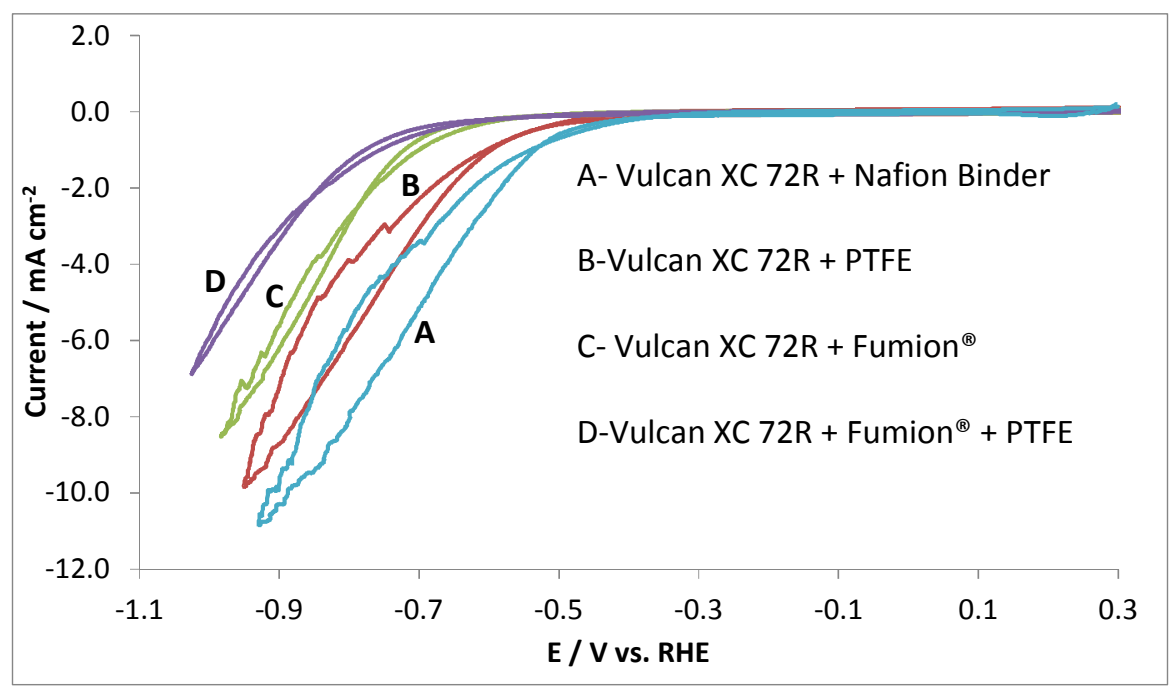

Figure 3. Cyclic voltammograms of the cathode electrocatalyst formulations in acid electrolyte at $10 \mathrm{mV} \mathrm{s}^{-1}$.

Electrochemical tests with the $50 \mathrm{mM}$ furfural solution were performed immediately after rinsing the electrodes with DI water. It can be observed in Figure 4 that a cathodic peak ca. -0.65 V vs. RHE appeared for all the electrode formulations, which can be attributed to the ECR of furfural. However, by comparing the current potential profiles in the absence and presence of furfural, it is clearly observed that the selectivity of furfural reduction over HER increases with the addition of hydrophobicity and/or substitution of ion exchange ionomer. An approximation of the current contribution of furfural reduction can then be obtained from the difference of the peak reduction current, and the background CV (in absence of furfural). For the electrocatalyst formulation D over $90 \%$ of the cathodic current observed at the peak potential (- $0.65 \mathrm{~V}$ vs. RHE) can be attributed to the furfural reduction. This is based on the current difference at the peak potential in the presence and absence of furfural. 

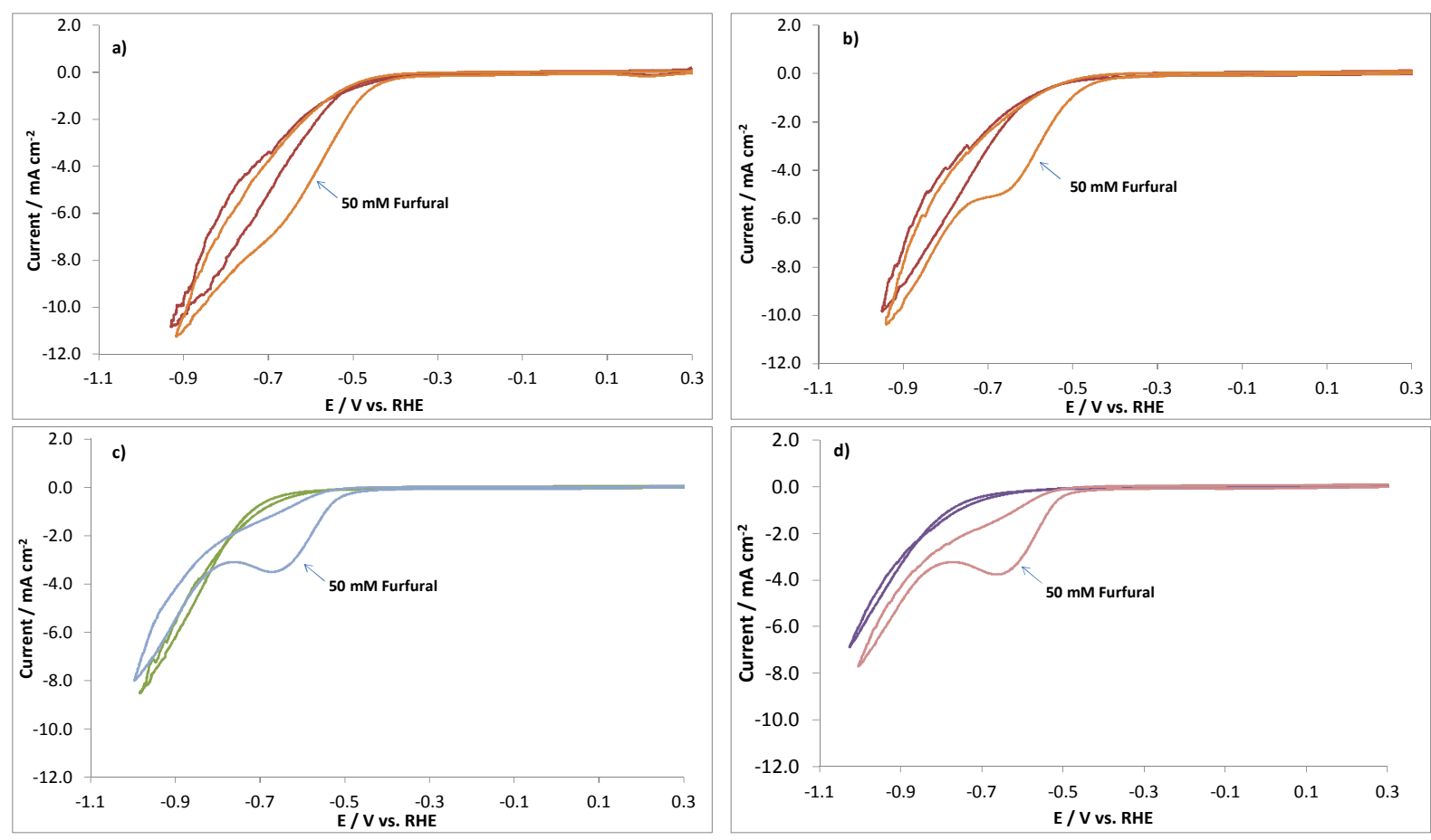

Figure 4. Cyclic voltammograms of the cathode electrocatalyst formulations in presence and absence of $50 \mathrm{mM}$ furfural in acid electrolyte at $10 \mathrm{mV} \mathrm{s}^{-1}$. a) formulation $\mathrm{A}, \mathrm{b}$ ) formulation $\mathrm{B}, \mathrm{c}$ ) formulation $\mathrm{C}$, and d) formulation $\mathrm{D}$.

The higher $\mathrm{pH}$ and/or restricted protic environment generated on the cathode surface should affect the reduction mechanism of furfural. In a proton rich media, the hydrogen addition is determined by acid base equilibria and can occur simultaneously with electron transfer. ${ }^{11,22,31}$ However, at higher $\mathrm{pH}$ or proton limited environments, the ECR of the carbonyl group will proceed without protonation forming a ketyl radical in a single electron transfer reaction. Thus, hydrogen addition will proceed using available protons or through the abstraction of hydrogen from water or solvent. ${ }^{31}$

The radical formation mechanisms in acid and alkaline media are discussed in detail by Ludvík $(2015)^{31}$ and depicted in Figure 5. The formed radicals will proceed to further reduce or 
the form dimers. The stability of the ketyl radical is enhanced by the presence of an aromatic ring or olefinic system in the $\alpha$-position. ${ }^{31}$

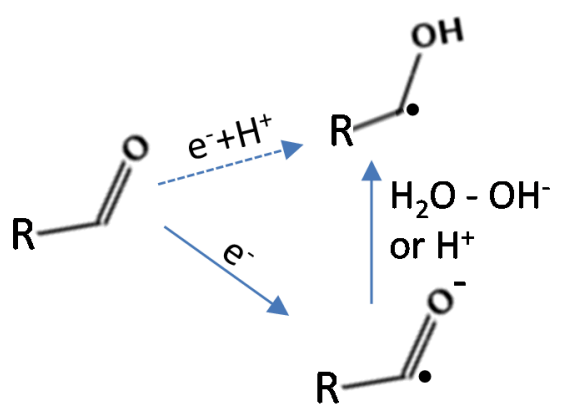

\section{Acid media}

Alkaline media

Figure 5. Possible pathways of the first electron transfer process in the electrochemical reduction of furfural.

The results shown in Figure 4 support the hypothesis that the modification of the cathode formulation can contribute to the control of the hydrogen source, enhancing the selectivity of the organic reduction. Formulation D was then selected for further electrochemical analysis. After the electrochemical tests with the furfural solution, the electrodes were rinsed with DI water and re-tested in the absence of furfural displaying a current potential profile similar to that presented in Figure 3.

CVs of the surrogate mixture, and individually for all the surrogates, were performed in a quiescent solution using catalyst formulation D. CVs of the individual surrogates are presented in Figure S3. Figure 6 shows the first and third CVs for the surrogate mixture. A well-defined cathodic current, with two separate shoulders ca. -0.65 and -0.85 V vs. RHE, was observed. An anodic peak ca. $0.3 \mathrm{~V}$ vs. RHE was also observed, likely due to the oxidation of reduction products from benzaldehyde and acetophenone, as suggested by the individual CVs in Figure S3. The comparison of the first and third CV cycle shows a decrease in the reduction current density. It is unlikely that the observed decrease in the current density can be attributed to the depletion 
of reagents due to the relatively low currents. Loss in electrocatalyst activity due to electrocatalyst poisoning, presumably caused by intermediates or products adsorbed on the catalyst surface, could better explain the decrease in current density.

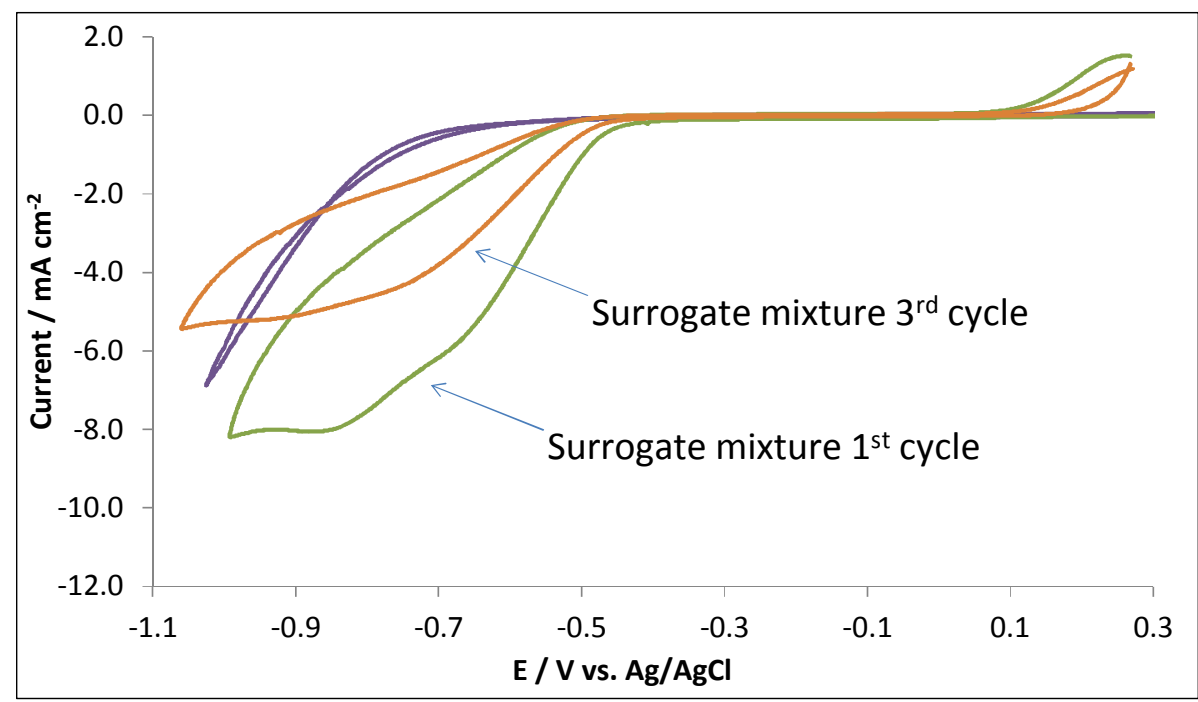

Figure 6. CVs of the cathode electrocatalyst formulations D in presence and absence of a $50 \mathrm{mM}$ furfural, benzaldehyde, phenol, p-methoxythiophenol, acetophenone, and valeraldehyde in the acid electrolyte at $10 \mathrm{mV} \mathrm{s}^{-1}$. Anodic current observed after $0 \mathrm{~V}$ vs. RHE shows the oxidation of reduction products.

Stepped potential experiments in the surrogate mixture were performed under RDE rotation at $1000 \mathrm{rpm}$ from -0.5 to $-1.5 \mathrm{~V}$ vs. $\mathrm{Ag} / \mathrm{AgCl}(0$ to $-1 \mathrm{~V}$ vs. RHE) with a step of $250 \mathrm{mV}$ and an interval time of five minutes. Stepped experiments allowed the evaluation of the electrocatalyst formulation under hydrodynamically controlled conditions. A rough estimation of the current efficiency for the reduction of the organic molecules can be obtained by calculating the percentage of the current density generated by the reduction of the organic molecules, assuming the HER current contribution as the base line. Figure 7 shows the current potential profiles for: a) the potential step experiments; and b) the estimation of the current efficiency at different 
electrode polarizations over the base of the HER. Although this experiment does not accurately calculate the current distribution towards each one of the possible reactions (ECR vs. HER), the current increase observed in the presence of surrogates is directly attributable to the reduction of the organic molecules. Therefore, this estimation provides an approximation of the minimum amount of current that goes towards ECR vs. HER. The results on Figure $7 \mathrm{~b}$ also provide valuable information regarding the ideal cathode potential operating range. The results are only an estimate, as some of the surrogates suppress the HER (Figure S3). A switch in the current magnitude, for the acid electrolyte and surrogate mixture, is observed at high potentials. Adsorbed intermediates and products formed in the presence of the organic surrogates could be causing the suppression of the HER. ${ }^{15}$
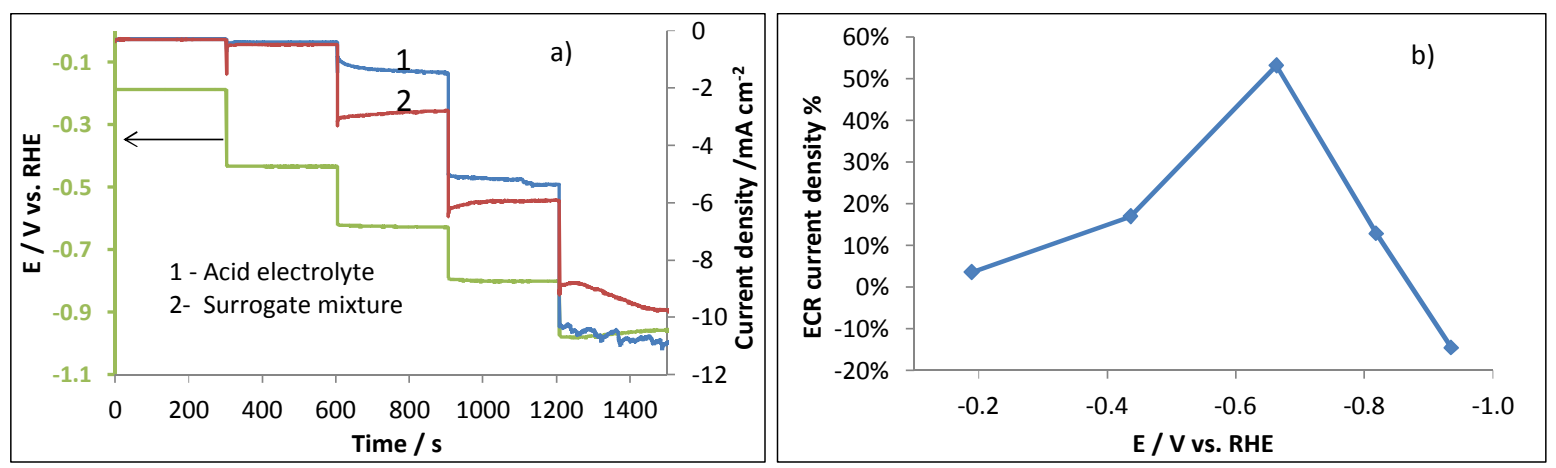

Figure 7. a) Current a potential profiles for the cathode electrocatalyst formulations D in presence and absence of a $50 \mathrm{mM}$ furfural, benzaldehyde, phenol, p-methoxythiophenol, acetophenone, and valeraldehyde in the acid electrolyte. b) Minimum percentage of current density that can be directly assigned to the ECR of the organic surrogates.

MEAs with $1.602 \mathrm{~cm}^{2}$ electrodes were prepared using formulation D on Nafion $\AA-117$ and Fumasep ${ }^{\circledR}$ FAA-3-PK-130 membranes. The MEAs were mounted between the two halves of the H-cell as described in Figure S1. The cathode solution contained acid electrolyte, while the anode compartment contained only DI water. CVs of the MEAs prepared with the Nafion ${ }^{\circledR}$ and 
Fumasep ${ }^{\circledR}$ membranes, in the absence of furfural (Figure S3), show that the protons transferred through the Nafion ${ }^{\circledR}$ (cation exchange) membrane result in a significantly more positive onset potential for the HER. When the Nafion ${ }^{\circledR}$ membrane was used, the cathode potential could not be increased beyond $-0.7 \mathrm{~V}$ vs. RHE due to the current limitation of the potentiostat (profuse HER). When the Fumasep ${ }^{\circledR}$ membrane was used, a significant negative shift in the HER was observed as the mechanism could have changed to HER in alkaline media (Reaction R2). Additional ionic resistance attributed to the lower conductivity of the Fumasep ${ }^{\circledR}$ membrane, in comparison with the Nafion ${ }^{\circledR}$ membrane, also explain lower current densities for the AEMMEA.

CVs obtained for both cation and anion MEAs, in the presence and absence of furfural, are presented in Figure 8. When the Nafion ${ }^{\circledR}$ membrane was used in the presence of furfural, the HER appeared to be suppressed, possibly due to the adsorption of furfural onto the catalyst; ${ }^{15}$ whereas with the Fumasep ${ }^{\circledR}$ membrane, a small shoulder was observed ca. $-0.7 \mathrm{~V}$ vs. RHE, in agreement with the results presented in Figure 4. Nevertheless, the distinct furfural reduction shoulder is less pronounced.
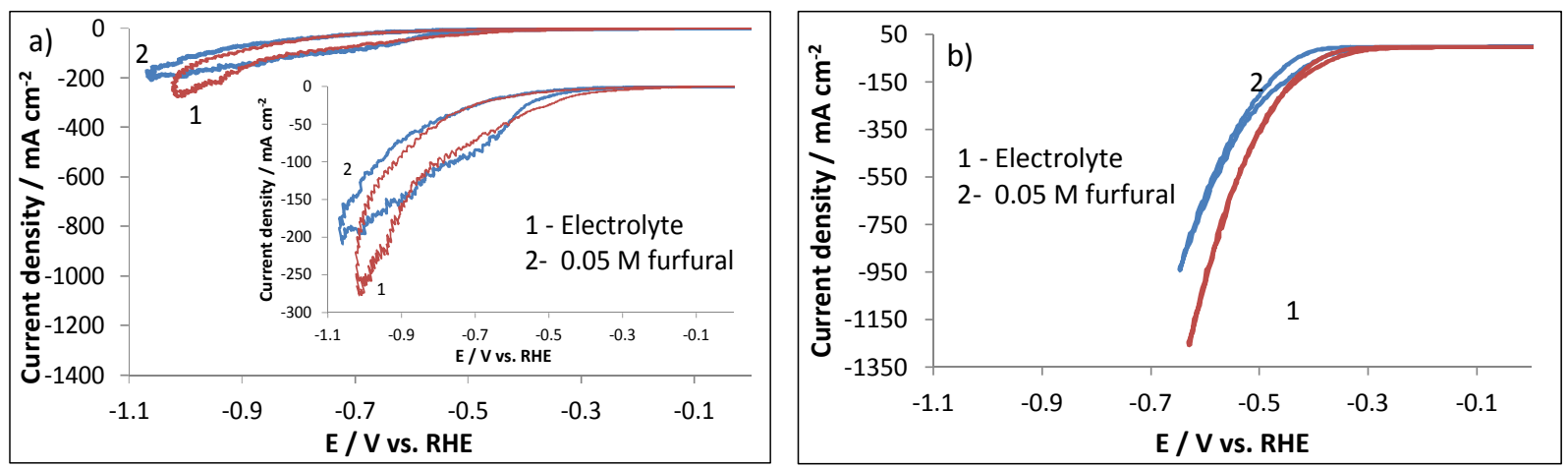

Figure 8. CVs obtained at $10 \mathrm{mV} \mathrm{s}^{-1}$ in the H-cell for a) Fumasep MEA and b) Nafion MEA in presence and absence of $0.05 \mathrm{M}$ furfural. Inset in figure a) zoom in the current potential profile. 
Constant current experiments were performed with the furfural and surrogate solutions at a current density of $100 \mathrm{~mA} \mathrm{~cm}^{-2}$ for both Nafion ${ }^{\circledR}$ and Fumasep ${ }^{\circledR}$ MEAs in the H-cell. For the Nafion ${ }^{\circledR}$ MEA, quantitative analysis of the furfural concentration in the catholyte solution after eight hours of applied current indicated negligible furfural conversion. No products were detected in the furfural catholyte. However, GC-MS qualitative analysis of the catholyte surrogate mixture (Figure S5) showed the formation of benzyl alcohol and styrene possibly produced after the reduction of acetophenone to phenyl ethanol and subsequent dehydration. Nevertheless, the significantly low conversions showed that the HER proceeds preferentially as the protons are transferred through the membrane directly to the electrocatalyst.

When the Fumasep ${ }^{\circledR}$ MEA was used, furfural reduction proceeded for approximately six hours as the cathode potential increased from to $-1.2 \mathrm{~V}$ vs. RHE to a maximum of $-2.1 \mathrm{~V}$ vs. RHE after $3.7 \mathrm{~h}$. Then the potential stabilized ca. $-1.9 \mathrm{~V}$ vs. RHE for $2.2 \mathrm{~h}$. The cathode potential profile is shown in Figure S6. After $5.9 \mathrm{~h}$ a sudden decrease in the cathode potential was recorded. This decrease in cathode potential was caused by the oxidation of the Pt coated sintered titanium anode to the point that electrical contact was lost, forcing a decrease of the current applied by the potentiostat. Due to the fact that the cathode potential was stable during the first $5.9 \mathrm{~h}$ of operation while the anode was being oxidized, it is possible that the anode oxidation could have been caused by anion transfer resistance through the membrane or on the anode side. Also, organic molecules could have fouled the membrane, thus avoiding the transference of hydroxyl ions. The use of an alkaline solution as anolyte was then proposed as alternative to avoid anode oxidation. Regardless of the experiment termination, without completion, the catholyte volume was reduced from 15 to $5 \mathrm{~mL}$ and a furfural conversion of 95.9\% (reacted furfural) was measured. For this experiment, no furfural was detected in the 
anolyte solution. GC-MS analysis showed hydrofuroin as the main product of the furfural reduction. High selectivity of carbon electrodes to hydrofuroin has been previously reported in H-Cell configurations (no MEA) using a cation exchange membrane and acetonitrile as electrolyte. ${ }^{16}$ When the surrogate mixture was tested in the Fumasep ${ }^{\circledR}$ MEA, the catholyte solution rapidly transferred to the anolyte compartment. Additionally, the membrane showed signs of disintegration, which was possibly caused by at least one of the constituents present in the surrogate mixture. Due to the aforementioned membrane stability issues, bulk electrolysis experiments were narrowed to furfural conversion.

\section{Bulk electrolysis}

Experimental reduction tests were performed at constant current $\left(50 \mathrm{~mA} \mathrm{~cm} \mathrm{~cm}^{-2}\right.$ during 30 and $60 \mathrm{~min}$ ) in a $10 \mathrm{~cm}^{2}$ flow cell using a Fumasep ${ }^{\circledR}$ MEA prepared with the cathode formulation D. On the cathode side $0.1 \mathrm{M}$ furfural solutions was circulated in the presence and absence of acid electrolyte, while $1 \mathrm{M} \mathrm{KOH}$ was fed to the anode to avoid electrode oxidation. The results in Table 1 show that furfural reached nearly complete conversion within the first 30 minutes of reaction. Chromatograms of the final products are shown in the supporting information, Figure S7. Traces of furfural that were detected in the anolyte did not exceed $0.25 \%$ of the initial furfural loaded in the system. However, this furfural was also counted to calculate the total furfural conversion $(X)$ as shown in Equation 1,

$$
X=\frac{V_{C}^{i} C_{C}^{i}-V_{C}^{f} C_{C}^{f}-V_{A}^{f} C_{A}^{f}}{V_{C}^{i} C_{C}^{i}}
$$

where $V$ and $C$ are the volume and concentration, subscripts $A$ and $C$ correspond to anolyte and catholyte, and superscript $i$ and $f$ are for initial and final, respectively. 
Table 1. Electrochemical reduction of furfural in anion exchange MEA. Initial solutions volumes for anolyte and catholyte were 5 and $10 \mathrm{~mL}$, respectively.

\begin{tabular}{|c|c|c|c|c|c|c|c|c|c|c|}
\hline \multirow[b]{2}{*}{$\begin{array}{l}\text { Cathode } \\
\text { electrolyte }\end{array}$} & \multirow[b]{2}{*}{$\begin{array}{l}\text { Time } \\
\text { min }\end{array}$} & \multirow[b]{2}{*}{$\begin{array}{c}\text { Charge } \\
\text { C }\end{array}$} & \multirow[b]{2}{*}{$\mathrm{pH}$} & \multicolumn{3}{|c|}{ Catholyte final } & \multicolumn{3}{|c|}{ Anolyte final } & \multirow[b]{2}{*}{$X$} \\
\hline & & & & $\begin{array}{c}\text { Volume } \\
\mathrm{mL}\end{array}$ & $\mathrm{pH}$ & $\begin{array}{c}\text { Furfural } \\
\mathrm{mM}\end{array}$ & $\begin{array}{c}\text { Volume } \\
\mathrm{mL}\end{array}$ & $\mathrm{pH}$ & $\begin{array}{c}\text { Furfural } \\
\mathrm{mM}\end{array}$ & \\
\hline $\begin{array}{l}5 \% \text { Acetic/ } \\
3 \% \text { Formic }\end{array}$ & 30 & 900 & 1.8 & 7.3 & 2.5 & 5.33 & 6.2 & 9.5 & 0.44 & 0.96 \\
\hline $\begin{array}{l}5 \% \text { Acetic/ } \\
3 \% \text { Formic }\end{array}$ & 60 & 1800 & 1.8 & 5.3 & 3.6 & 5.33 & 8.9 & 3.7 & 0.39 & 0.97 \\
\hline DI water & 30 & 900 & 3.1 & 9.5 & 12.5 & 5.81 & 4.5 & 13.3 & 0.35 & 0.94 \\
\hline DI water & 60 & 1800 & 3.1 & 9.3 & 13.2 & 6.31 & 4.8 & 13.5 & 0.44 & 0.94 \\
\hline
\end{tabular}

Hydrofuroin along with traces of furoin were identified as the main products from the ECR of furfural for both catholyte formulations. GC-MS analysis of unreacted catholyte solutions, also showed the presence of furoin and hydrofuroin, but in significantly lower amounts. Possible combination of chemical and electrochemical reactions as reported by other researchers may be occurring. ${ }^{19}$ Chadderon et al $2017^{11}$ suggested the simultaneous addition hydrogen and electrons to generate a hydroxyl radical, which dimerizes to form hydrofuroin. However, at higher $\mathrm{pH}$ or in proton restricted environments, the electron transfer mechanism proceeds without the addition of protons to form a ketyl radical as shown in Figure 5. The ketyl radical is then hydrogenated to form the hydroxyl radical, which dimerizes to hydrofuroin (Figure 9). An alternate but less probable route is the radical-radical dimerization among the ketyl and hydroxyl radical to form furoin, which can also be reduced to form hydrofuroin. ${ }^{32}$ 2,2'-(1,2-Ethenediyl)difuran was also observed, for both catholytes, as product of the dehydration of hydrofuroin. Although little attention has been paid to furfural reduction products beyond furfuryl alcohol and 2-methyl furan, $\mathrm{C}_{10}$ products such as furoin and hydrofuroin can be used as intermediates for the production of diesel fuel substitutes. ${ }^{33}$ 


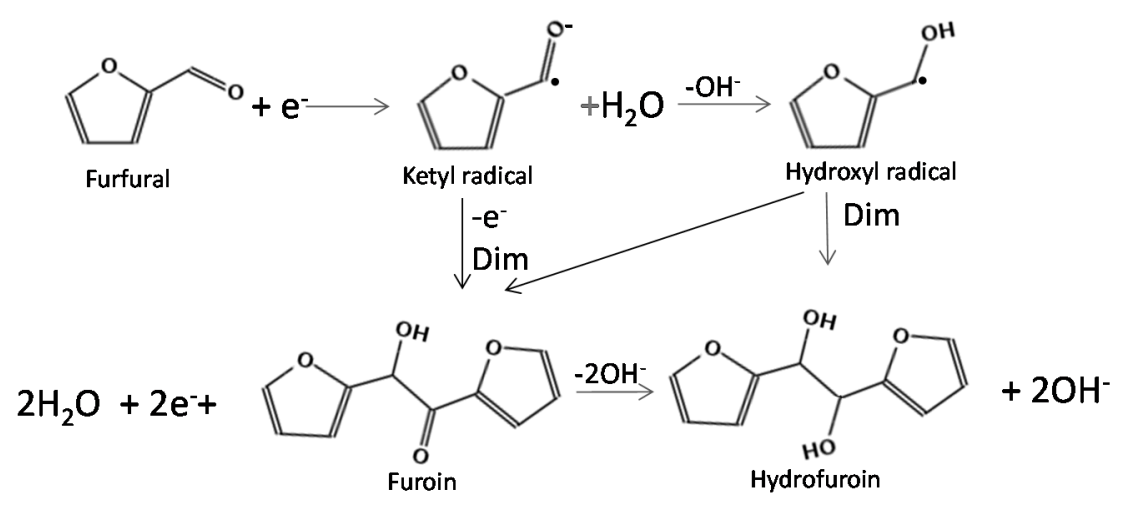

Figure 9. Hydrofuroin formation through electrochemical reduction of furfural

Cyclopentanedione and glutaraldehyde were also detected as products in the catholyte with acid electrolyte. Although no quantitative analysis was performed, the peak area ratio of glutaraldehyde to cyclopentanedione increased from 0.91 to 1.82 for 30 and 60 min of applied current, respectively. This suggests that glutaraldehyde could be formed by the reduction of cyclopentanedione as presented in Figure 10. No cyclopentanedione or glutaraldehyde were observed on the catholyte in the absence of electrolyte. $\mathrm{pH}$ has been demonstrated to be a major factor in the product selectivity for furfural reduction. ${ }^{19}$

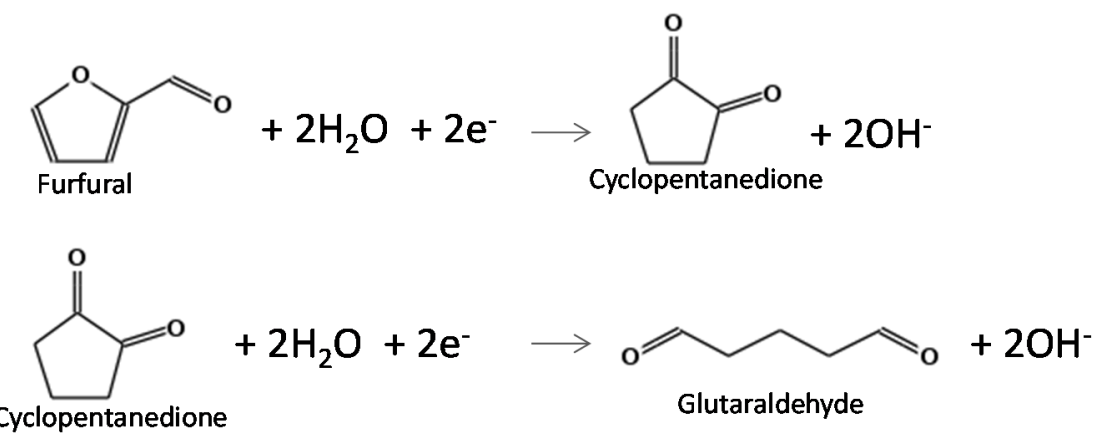

Figure 10. Glutaraldehyde formation through electrochemical reduction of furfural

Furfuryl alcohol was another of the products observed, in small quantities, for both catholyte formulations. During the first $30 \mathrm{~min}$, the reduction selectivity to furfuryl alcohol was only 
$0.45 \%$ for the catholyte with acid electrolyte and $0.97 \%$ for the catholyte without electrolyte. The same furfuryl alcohol selectivity ( $0.97 \%)$ was obtained for the catholyte solution in absence of electrolyte after 60 min of reaction.

For the catholyte with acid electrolyte, furfuryl alcohol was not detected after 60 min of reaction. If formed, the most likely product from the reduction of furfuryl alcohol, 2-methyl furan, could have been lost due to its high volatility. Previous work by other researchers have showed that a cold trap was needed to capture 2-methyl furan. ${ }^{16,19}$ Nevertheless, 5-methyl-2furfurylfuran was observed in the catholyte with acid electrolyte after 30 min of reaction, which could suggest the polymerization of furfuryl alcohol as another possible reaction. ${ }^{34,35}$ Neither furfuryl alcohol, nor 5-methyl-2-furfurylfuran were detected in the 60 min reaction experiment. However, the formation of a brown color resin on the surface of the tubing used for catholyte recirculation could indicate polymerization products. Analysis of the resin was not performed. Other peaks were observed on the chromatograms but it was not possible to obtain a good match from the MS database.

The results in Table 1 also show changes in the volume and $\mathrm{pH}$ of the anolyte and catholyte solutions. When acid electrolyte is present in the catholyte, formate and acetate anions are transferred through the membrane, rather than hydroxyl ions, causing the decrease of the anolyte $\mathrm{pH}$. A significant change in the solution's volume was observed due the electro-osmotic transfer of water from cathode to anode. Thus, anion exchange MEAs can also be used to separate the small carboxylic acids present biomass hydrolysates, while concentrating the final product. ${ }^{36}$ In the absence of electrolyte, the $\mathrm{pH}$ of the catholyte solution increased to equilibrate with the anolyte $\mathrm{pH}$. The significant increase in the catholyte $\mathrm{pH}$ confirms the production of hydroxyl ions from either the HER or the ECR. 
Cell potential profiles for the 30 and 60 minutes bulk ECR experiments, in the presence and absence of electrolyte, are presented in Figure 11. A higher cell potential is observed for the experiments performed in the absence of electrolyte. Transfer of small carbonyl acids through the membrane significantly contribute to ionic conductivity and to a lower cell potential, which explains the increase of cell potentials with time as acetic and formic acids are transferred to the anolyte. In the absence of electrolytes, the significant differences among the potential profiles are observed obtained during the 30 and 60 minute experiments could be attributed to the order in which the experiments were performed. Because the 60 minute experiment was first performed in the absence of electrolyte, just after the experiments with the acid electrolyte. Traces of formate and acetate that could have remained in the system and membrane after cleaning could have contributed to the lower cell potential.

The lower cell potentials featured in the presence of acid electrolyte, and the significant $\mathrm{pH}$ increases observed in the absence of electrolyte for the catholyte solutions, could align with the hypothesis that organic molecules can be impeding the transfer of hydroxyl ions. On the other hand, these phenomena can also be explained by changes on the membrane and/or ionomer functionalization, in which the formate and acetate ions substitute the hydroxyl ions. Thus, a deep analysis in membrane functionalization and fouling is recommended for future research. 


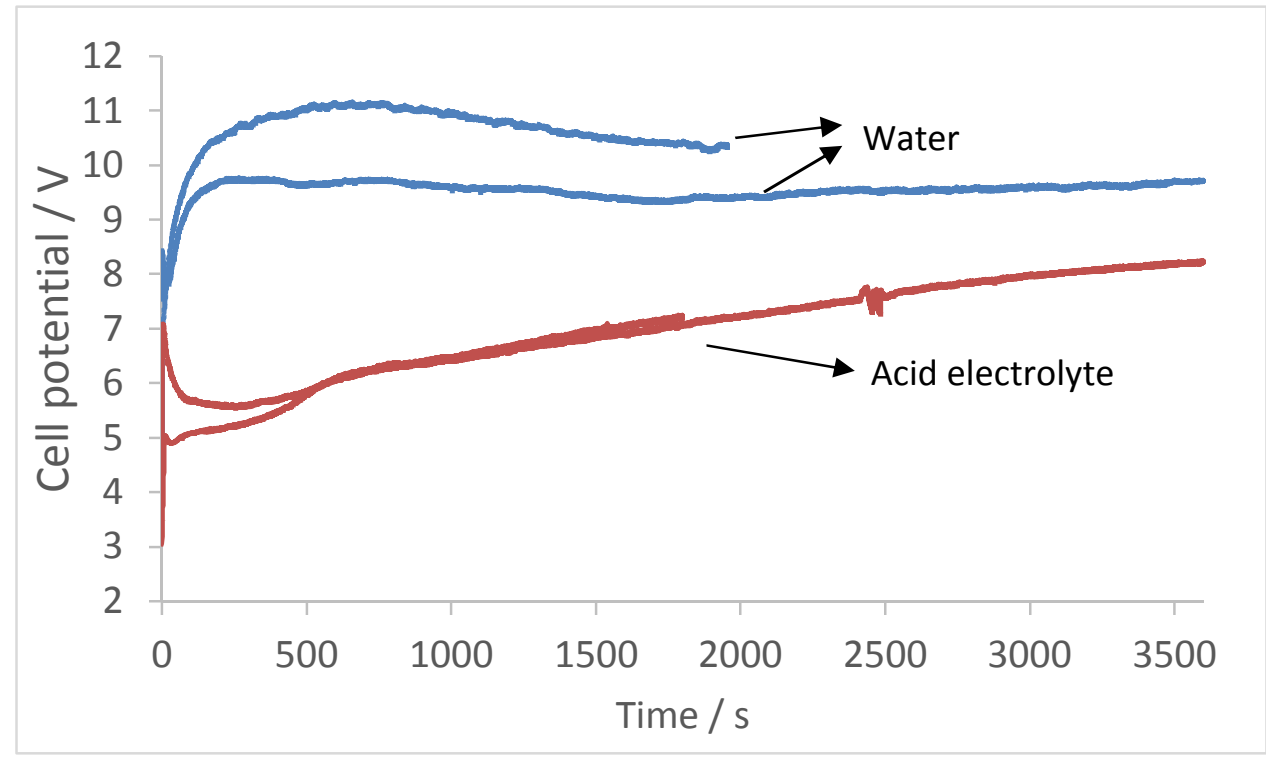

Figure 11. Cell potential profiles for the bulk reduction of furfural in the presence and absence of acid electrolyte

\section{Conclusions}

AEMs employed in a MEA configuration were successfully used for the efficient reduction of furfural on carbon electrodes and in the absence of electrolyte. High furfural conversions (reduction) were achieved using a metal free electrocatalyst, which showed preference towards the formation of dimerized furfural products. Although it was not studied in this paper, the use of metal supported catalysts is expected to improve the selectivity of the reduction reactions to other products. The use of AEI in the cathode along PTFE in the cathode formulation allowed a significant increase in the HER overpotential, while enhancing the ECR reduction of BDPM.

Although HER will always compete with the ECR regardless of the $\mathrm{pH}$ of the electrolyte media, the proton concentration on the cathode electrocatalyst and, therefore, the HER can be better controlled using AEM-MEA vs. CEM-MEA. When a CEM is used, hydrogen protons 
transferred through the membrane will readily find the catalyst membrane interface, which is the zone with the highest current distribution, enhancing the HER almost exclusively. By using an AEM, the source of hydrogen does not come through the membrane, but from protons present in solution and/or abstracted from the solvent (i.e. water). Then, the addition of hydrophobicity and/or modification of the transport properties of the electrocatalyst can lead to the generation of a higher $\mathrm{pH}$ and/or restricted protic environment on the cathode surface, which will contribute to a decrease in the efficiency of hydrogen evolution by limiting the transport of the hydrogen source.

As an additional advantage, AEM can contribute to facilitation of water management. As the electro-osmotic transfer of water proceeds in the direction of ion transfer, the use of a CEM will cause the continuous dilution of the catholyte through the transfer of water from the anode to the cathode. However, the opposite scenario is observed with the use of AEM, as presented in Table 1.

AEM electrolyzers are shown to be a feasible option for the electrochemical upgrading of BDPM. However, membrane stability, conductivity, and resistance to fouling should be addressed in order to achieve a feasible implementation for this technology.

\section{Acknowledgements}

This work is supported by the U.S. Department of Energy, Office of Energy Efficiency and Renewable Energy, Bioenergy Technologies Office. This manuscript has been authored by Battelle Energy Alliance, LLC under Contract No. DE-AC07-05ID14517.

\section{Associated content:}


Supporting information: Figure S1 scheme of H-Cell, Figure S2 Nyquist plot for the H-cell with electrode formulation D for the CEM and AEM, Figure S3 individual CVs of molecules present in the surrogate mixture, Figure S4 CVs of the anion and cation exchange MEAs in the H-cell, Figure S5 chromatogram of the surrogate mixture after processing in the CEM, Figure S6 potential profile for the bulk reduction of $0.05 \mathrm{M}$ furfural at $100 \mathrm{~mA} \mathrm{~cm}{ }^{-2}$ using an AEM (1) and a CEM (2) in the H-Cell, S7 chromatogram of the furfural electrochemical reduction after $30 \mathrm{~min}$ in the flow cell.

\section{References}

1. Holladay, J. E.; White, J. F.; Bozell, J. J.; Johnson, D. Top Value-Added Chemicals from BiomassVolume II-Results of Screening for Potential Candidates from Biorefinery Lignin; Pacific Northwest National Laboratory (PNNL), Richland, WA (US): 2007.

2. de Jong, E.; Jungmeier, G., Biorefinery concepts in comparison to petrochemical refineries. In Ind. Biorefin. White Biotechnol., Pandey, A.; Hofer, R.; Larroche, C.; Taherzadeh, M.; Nampoothiri, M., Eds. 2015.

3. Dumeignil, F.; Capron, M.; Katryniok, B.; Wojcieszak, R.; Löfberg, A.; Girardon, J.-S.; Desset, S.; Araque-Marin, M.; Jalowiecki-Duhamel, L.; Paul, S., Biomass-derived Platform Molecules Upgrading through Catalytic Processes: Yielding Chemicals and Fuels. J. Jpn. Pet. Inst. 2015, 58 (5), DOI 10.1627/jpi.58.257.

4. Mohan, D.; Pittman, C. U.; Steele, P. H., Pyrolysis of Wood/Biomass for Bio-oil: A Critical Review. Energy Fuels 2006, 20 (3), DOI 10.1021/ef0502397.

5. $\quad \mathrm{Xu}, \mathrm{Y}$.; Qiu, S.; Long, J.; Wang, C.; Chang, J.; Tan, J.; Liu, Q.; Ma, L.; Wang, T.; Zhang, Q., In situ hydrogenation of furfural with additives over a RANEY[registered sign] Ni catalyst. RSC Adv. 2015, 5 (111), DOI 10.1039/C5RA12844G.

6. Talmadge, M. S.; Baldwin, R. M.; Biddy, M. J.; McCormick, R. L.; Beckham, G. T.; Ferguson, G. A.; Czernik, S.; Magrini-Bair, K. A.; Foust, T. D.; Metelski, P. D.; Hetrick, C.; Nimlos, M. R., A perspective on oxygenated species in the refinery integration of pyrolysis oil. Green Chem. 2014, 16 (2), DOI 10.1039/C3GC41951G. 
7. Mariscal, R.; Maireles-Torres, P.; Ojeda, M.; Sadaba, I.; Lopez Granados, M., Furfural: a renewable and versatile platform molecule for the synthesis of chemicals and fuels. Energy Environ. Sci. 2016, 9 (4), DOI 10.1039/C5EE02666K.

8. González, C.; Marín, P.; Díez, F. V.; Ordóñez, S., Hydrodeoxygenation of Acetophenone over Supported Precious Metal Catalysts at Mild Conditions: Process Optimization and Reaction Kinetics. Energy Fuels 2015, 29 (12), DOI 10.1021/acs.energyfuels.5b02112.

9. Jones, S.; Meyer, P.; Snowden-Swan, L.; Padmaperuma, A.; Tan, E.; Dutta, A.; Jacobson, J.; Cafferty, K. Process design and economics for the conversion of lignocellulosic biomass to hydrocarbon fuels; PNNL, NREL, INL: 2013.

10. Song, Y.; Chia, S. H.; Sanyal, U.; Gutiérrez, O. Y.; Lercher, J. A., Integrated catalytic and electrocatalytic conversion of substituted phenols and diaryl ethers. J. Catal. 2016, 344, DOI 10.1016/j.jcat.2016.09.030.

11. Chadderdon, X. H.; Chadderdon, D. J.; Matthiesen, J. E.; Qiu, Y.; Carraher, J. M.; Tessonnier, J.P.; Li, W., Mechanisms of Furfural Reduction on Metal Electrodes: Distinguishing Pathways for Selective Hydrogenation of Bioderived Oxygenates. J. Am. Chem. Soc. 2017, 139 (40), DOI 10.1021/jacs.7b06331.

12. Li, Z.; Kelkar, S.; Lam, C. H.; Luczek, K.; Jackson, J. E.; Miller, D. J.; Saffron, C. M., Aqueous electrocatalytic hydrogenation of furfural using a sacrificial anode. Electrochim. Acta 2012, 64, DOI 10.1016/j.electacta.2011.12.105.

13. Amouzegar, K.; Savadogo, O., Electrocatalytic hydrogenation of phenol on highly dispersed Pt electrodes. Electrochim. Acta 1994, 39 (4), DOI 10.1016/0013-4686(94)80101-0.

14. dos Santos, T. R.; Nilges, P.; Sauter, W.; Harnisch, F.; Schroder, U., Electrochemistry for the generation of renewable chemicals: electrochemical conversion of levulinic acid. RSC Adv. 2015, 5 (34), DOI 10.1039/C4RA16303F.

15. Nilges, P.; dos Santos, T. R.; Harnisch, F.; Schroder, U., Electrochemistry for biofuel generation: Electrochemical conversion of levulinic acid to octane. Energy Environ. Sci. 2012, 5 (1), DOI 10.1039/C1EE02685B.

16. Nilges, P.; Schröder, U., Electrochemistry for biofuel generation: production of furans by electrocatalytic hydrogenation of furfurals. Energy Environ. Sci. 2013, 6 (10), DOI 10.1039/C3EE41857J.

17. Sáez, A.; García-García, V.; Solla-Gullón, J.; Aldaz, A.; Montiel, V., Electrocatalytic hydrogenation of acetophenone using a Polymer Electrolyte Membrane Electrochemical Reactor. Electrochim. Acta 2013, 91, DOI 10.1016/j.electacta.2012.12.097.

18. Parpot, P.; Bettencourt, A. P.; Chamoulaud, G.; Kokoh, K. B.; Belgsir, E. M., Electrochemical investigations of the oxidation-reduction of furfural in aqueous medium: Application to electrosynthesis. Electrochim. Acta 2004, 49 (3), DOI 10.1016/j.electacta.2003.08.021.

19. Jung, S.; Biddinger, E. J., Electrocatalytic Hydrogenation and Hydrogenolysis of Furfural and the Impact of Homogeneous Side Reactions of Furanic Compounds in Acidic Electrolytes. ACS Sustainable Chem. Eng. 2016, DOI 10.1021/acssuschemeng.6b01314.

20. Benziger, J.; Nehlsen, J., A Polymer Electrolyte Hydrogen Pump Hydrogenation Reactor. Ind. Eng. Chem. Res. 2010, 49 (21), DOI 10.1021/ie100631a.

21. Li, Z.; Garedew, M.; Lam, C. H.; Jackson, J. E.; Miller, D. J.; Saffron, C. M., Mild electrocatalytic hydrogenation and hydrodeoxygenation of bio-oil derived phenolic compounds using ruthenium supported on activated carbon cloth. Green Chem. 2012, 14 (9), DOI 10.1039/C2GC35552C.

22. Song, Y.; Sanyal, U.; Pangotra, D.; Holladay, J. D.; Camaioni, D. M.; Gutiérrez, O. Y.; Lercher, J. A., Hydrogenation of benzaldehyde via electrocatalysis and thermal catalysis on carbon-supported metals. J. Catal. 2018, 359, DOI 10.1016/j.jcat.2017.12.026.

23. Pintauro, P. N.; Gil, M. P.; Warner, K.; List, G.; Neff, W., Electrochemical Hydrogenation of Soybean Oil with Hydrogen Gas. Ind. Eng. Chem. Res. 2005, 44 (16), DOI 10.1021/ie0490738. 
24. Vilar, M.; Oliveira, J. L.; Navarro, M., Investigation of the hydrogenation reactivity of some organic substrates using an electrocatalytic method. Appl. Catal., A 2010, 372 (1), DOI 10.1016/j.apcata.2009.09.041.

25. Carroll, K. J.; Burger, T.; Langenegger, L.; Chavez, S.; Hunt, S. T.; Román-Leshkov, Y.; Brushett, F. R., Electrocatalytic Hydrogenation of Oxygenates using Earth-Abundant Transition-Metal Nanoparticles under Mild Conditions. ChemSusChem 2016, 9 (15), DOI 10.1002/cssc.201600290.

26. Green, S. K.; Tompsett, G. A.; Kim, H. J.; Kim, W. B.; Huber, G. W., Electrocatalytic Reduction of Acetone in a Proton-Exchange-Membrane Reactor: A Model Reaction for the Electrocatalytic Reduction of Biomass. ChemSusChem 2012, 5 (12), DOI 10.1002/cssc.201200416.

27. Xing, R.; Qi, W.; Huber, G. W., Production of furfural and carboxylic acids from waste aqueous hemicellulose solutions from the pulp and paper and cellulosic ethanol industries. Energy Environ. Sci. 2011, 4 (6), DOI 10.1039/C1EE01022K.

28. Ringer, M.; Putsche, V.; Scahill, J. Large-Scale Pyrolysis Oil Production: A Technology Assessment and Economic Analysis NREL: 2006.

29. He, W.; Nguyen, T. V., Edge Effects on Reference Electrode Measurements in PEM Fuel Cells. J. Electrochem. Soc. 2004, 151 (2), DOI 10.1149/1.1634272.

30. Kuwertz, R.; Martinez, I. G.; Vidaković-Koch, T.; Sundmacher, K.; Turek, T.; Kunz, U., Material development and process optimization for gas-phase hydrogen chloride electrolysis with oxygen depolarized cathode. J. Appl. Electrochem. 2016, 46 (7), DOI 10.1007/s10800-016-0966-9.

31. Ludvík, J., Reduction of Aldehydes Ketones and Azomethines. In Sustainable Energy Fuels, Hammerich, O.; Speiser, B., Eds. 2015; Vol. 5.

32. Andrieux, C. P.; Grzeszczuk, M.; Saveant, J. M., Electrochemical generation and reduction of organic free radicals.. alpha.-Hydroxybenzyl radicals from the reduction of benzaldehyde. J. Am. Chem. Soc. 1991, 113 (23), DOI 10.1021/ja00023a032.

33. James, O. O.; Maity, S.; Usman, L. A.; Ajanaku, K. O.; Ajani, O. O.; Siyanbola, T. O.; Sahu, S.; Chaubey, R., Towards the conversion of carbohydrate biomass feedstocks to biofuels via hydroxylmethylfurfural. Energy Environ. Sci. 2010, 3 (12), DOI 10.1039/B925869H.

34. Hallal, J. L. J.; Lucho, A. M. S.; Gonçalves, R. S., Electrochemical polymerization of furfural on a platinum electrode in aqueous solutions of potassium biphthalate. Mater. Res. (Sao Carlos, Braz.) 2005, 8, DOI 10.1590/S1516-14392005000100006

35. Kim, T.; Assary, R. S.; Kim, H.; Marshall, C. L.; Gosztola, D. J.; Curtiss, L. A.; Stair, P. C., Effects of solvent on the furfuryl alcohol polymerization reaction: UV Raman spectroscopy study. Catal. Today 2013, 205, DOI 10.1016/j.cattod.2012.09.033.

36. Lister, T. E.; Diaz, L. A.; Lilga, M. A.; Padmaperuma, A. B.; Lin, Y.; Palakkal, V. M.; Arges, C. G., Low-Temperature Electrochemical Upgrading of Bio-oils Using Polymer Electrolyte Membranes. Energy Fuels 2018, 32 (5), DOI 10.1021/acs.energyfuels.8b00134. 


\section{TOC/Abstract}

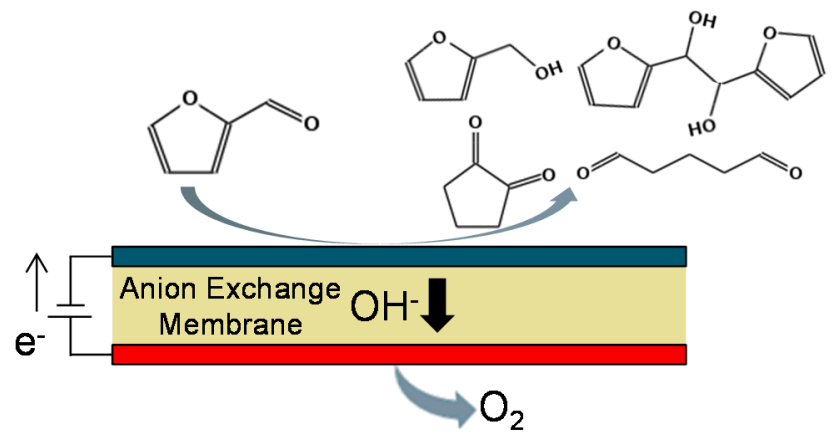

\section{Synopsis}

This paper assesses anion exchange membrane electrolyzers as alternative for the electrochemical upgrading of biomass, a sustainable pathway for valorization that can be directly fed by carbon free energy sources. 